\title{
Multisensory Stimulation to Improve Low- and Higher-Level Sensory Deficits after Stroke: A Systematic Review
}

\author{
Angelica Maria Tinga ${ }^{1}$ - Johanna Maria Augusta Visser-Meily ${ }^{2} \cdot$ \\ Maarten Jeroen van der Smagt ${ }^{1} \cdot$ Stefan Van der Stigchel $^{1}$. \\ Raymond van $\mathrm{Ee}^{3,4,5}$. Tanja Cornelia Wilhelmina Nijboer ${ }^{1,2}$
}

Received: 31 May 2015 / Accepted: 1 October 2015 /Published online: 21 October 2015

(C) The Author(s) 2015. This article is published with open access at Springerlink.com

\begin{abstract}
The aim of this systematic review was to integrate and assess evidence for the effectiveness of multisensory stimulation (i.e., stimulating at least two of the following sensory systems: visual, auditory, and somatosensory) as a possible rehabilitation method after stroke. Evidence was considered with a focus on low-level, perceptual (visual, auditory and somatosensory deficits), as well as higher-level, cognitive, sensory deficits. We referred to the electronic databases Scopus and PubMed to search for articles that were published before May 2015. Studies were included which evaluated the effects of multisensory stimulation on patients with low- or higher-level sensory deficits caused by stroke. Twenty-one studies were included in this review and the quality of these studies was assessed (based on eight elements: randomization, inclusion of control patient group, blinding of participants,
\end{abstract}

This study was performed at the Helmholtz Institute Utrecht, the Netherlands.

The manuscript or substantially similar work, has not been published and is not under consideration for publication elsewhere.

Artwork was created in Adobe Photoshop CS6 and Microsoft Word 2010.

Tanja Cornelia Wilhelmina Nijboer

t.c.w.nijboer@uu.nl

1 Department of Experimental Psychology, Hemholtz Institute, Utrecht University, Utrecht, The Netherlands

2 Brain Center Rudolf Magnus, and Center of Excellence for Rehabilitation Medicine, University Medical Center Utrecht, and De Hoogstraat Rehabilitation, Utrecht, The Netherlands

3 Department of Brain, Body \& Behavior, Philips Research Laboratories, Eindhoven, The Netherlands

4 Department of Biophysics, Donders Institute, Radboud University, Nijmegen, The Netherlands

5 Laboratory of Experimental Psychology, University of Leuven, Leuven, Belgium blinding of researchers, follow-up, group size, reporting effect sizes, and reporting time post-stroke). Twenty of the twenty-one included studies demonstrate beneficial effects on low- and/or higher-level sensory deficits after stroke. Notwithstanding these beneficial effects, the quality of the studies is insufficient for valid conclusion that multisensory stimulation can be successfully applied as an effective intervention. A valuable and necessary next step would be to set up well-designed randomized controlled trials to examine the effectiveness of multisensory stimulation as an intervention for low- and/or higher-level sensory deficits after stroke. Finally, we consider the potential mechanisms of multisensory stimulation for rehabilitation to guide this future research.

Keywords Stroke $\cdot$ Hemianopia $\cdot$ Perceptual disorders · Neglect $\cdot$ Rehabilitation $\cdot$ Multisensory $\cdot$ Review

\begin{tabular}{ll}
\multicolumn{2}{l}{ Abbreviations } \\
ADL & Activities of Daily Living \\
fMRI & Functional Magnetic Resonance Imaging \\
MSI & Multisensory Integration \\
RCT & Randomized Controlled Trial \\
A & Auditory \\
AV & Audiovisual \\
d & Days \\
Fr & Frontal \\
h & Hours \\
LH & Left Hemisphere \\
m & Months \\
ms & Milliseconds \\
Oc & Occipital \\
P & Proprioceptive \\
Pa & Parietal \\
RH & Right Hemisphere
\end{tabular}




$\begin{array}{ll}\text { S } & \text { Somatosensory } \\ \text { SC } & \text { Subcortical } \\ \text { Sign. } & \text { Statistically Significant } \\ \text { Te } & \text { Temporal } \\ \text { V } & \text { Visual } \\ \text { v } & \text { Years }\end{array}$

\section{Introduction}

In the last decade there has been a considerable increase in fundamental cognitive neuroscience studies on multisensory integration (MSI; Van der Stoep et al. 2015). Most of these studies indicate that multisensory integration allows for a coherent representation of the environment and that it enhances detection and localization of external events (see Stein 2012 for an overview). Combining information from different sensory modalities can be especially beneficial in supporting behavior when the signal from a single modality is only weakly able to induce a behavioral response, or when a sensory system as a whole is weakened (Stein 2012). Based on these findings, we hypothesize that stimulating multiple sensory modalities (i.e., multisensory stimulation) has the potential to be beneficial in improving sensory deficits after brain damage, as information from a normally functioning sensory modality might aid the processing of information from the impaired sensory modality. In this way, multisensory stimulation might have the potential to aid rehabilitation of patients suffering from stroke.

Integration of multisensory information is an important aspect of multisensory stimulation. Animal studies have led to the formulation of three fundamental rules of MSI (Stein 2012): first, the temporal rule states that maximal MSI occurs when multimodal stimulations occur approximately at the same time; second, the spatial rule states that maximal MSI occurs when multimodal stimulations originate from the same location; and third, the rule of inverse effectiveness states that maximal MSI occurs when each of the constituent unisensory stimuli are suboptimally effective in evoking responses.

Electrophysiological and anatomical findings in animals and non-invasive neuroimaging findings in humans have identified multiple brain areas that contribute to MSI (Amedi et al. 2001; Keysers et al. 2003; Rockland and Ojima 2003; Shore 2005; Nagy et al. 2006; Beauchamp et al. 2008; Allman et al. 2009; Cappe et al. 2009; Falchier et al. 2010). Two basic neural mechanisms by which multisensory processing can arise have been proposed. First, multisensory processing may be accomplished when primary sensory areas are activated and project to multisensory convergence areas (red arrows in Fig. 1), followed by feedback projections from the latter to the former. Second, neurophysiological studies in animals have demonstrated that there is a direct neural connectivity between the primary sensory cortices (Rockland and Ojima 2003; Allman et al. 2009; Falchier et al. 2010), which implies that sensory modalities can also modulate each other's responses at a low cortical level of processing (blue arrows in Fig. 1). Moreover, several fMRI (functional magnetic resonance imaging) studies have reported an increase or decrease in brain activity of the primary sensory cortices during multisensory stimulation (Macaluso et al. 2000; Amedi et al. 2002; Watkins et al. 2006; Martuzzi et al. 2007). For a more detailed discussion of brain areas that contribute to MSI, see for example Bolognini et al. (2013) and Klemen and Chambers (2012).

In general, the brain can use alternative routes to by-pass a damaged area after stroke and in this way adapt to the damage (e.g., Nudo et al. 1996; Dancause et al. 2005; Wilde et al. 2012; Buma et al. 2013). We expect that multisensory information could still be combined to some extent in the case of damage to multimodal association areas as well as when the damage affects sensory-specific cortices, because many (even sensory-specific) brain regions would still be able to assist in combining this information. Multisensory stimulation might even enhance residual neuronal activity within such a damaged area when information comes from multiple senses. This increase in neuronal activity might lead to (for instance) detection improvements, since neuronal activity is more likely to exceed the threshold necessary for detection. All in all, multisensory stimulation might prove to be a promising intervention for (sensory-specific) impairment caused by stroke, since information coming from multiple senses might enhance detection and localization of, and responding to external events, resulting in a reduction of the impairment.

The aim of the current systematic review is to provide an integrated account and quality assessment of studies that have investigated multisensory stimulation as a possible rehabilitation method to improve low-level and higher-level sensory deficits after stroke. Deficits in low-level processing of perceptual information occur at a relatively early processing stage, leading to a primary sensory deficit (e.g., visual field defects). Distortions at a later level of perceptual processing are causing higher-level sensory deficits, which are more cognitive in nature (e.g., neglect; Kandel et al. 2000). Recently, Johansson (2012) deemed multisensory stimulation in stroke rehabilitation a promising approach with a focus on motor recovery. Our focus will be on the effects of multisensory stimulation on recovery of sensory deficits. To guide future research, we also consider the mechanisms of multisensory stimulation for rehabilitation (i.e., the short- and long-term effects, transfer effects, and whether it targets compensation and/or restoration). In the next sections, studies that have assessed the effects of multisensory stimulation in patients with low-level visual (i.e., visual field defects), auditory and somatosensory deficits and higher-level sensory deficits (i.e., hemi-inattention or neglect) caused by stroke will be reviewed. 


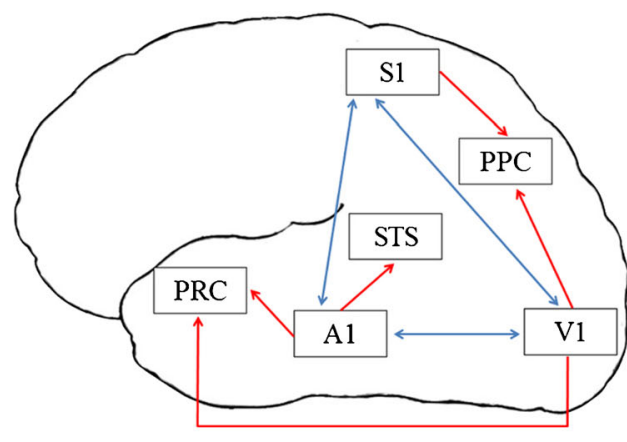

Fig. 1 An illustration of how multisensory processing could arise from projections from sensory specific areas to multisensory convergence areas (depicted in red) or from direct anatomical connections between the primary sensory areas (depicted in blue). Lateral view on the left, medial view on the right. Depicted multimodal areas: The posterior

\section{Methods}

\section{Literature Search and Article Selection}

The literature search (Fig. 2) was conducted in the Scopus and PubMed databases for articles that have been published before May 2015. Date last searched was May 5, 2015. The string used to search for articles was: (TITLE-ABS-KEY ("multisensory"

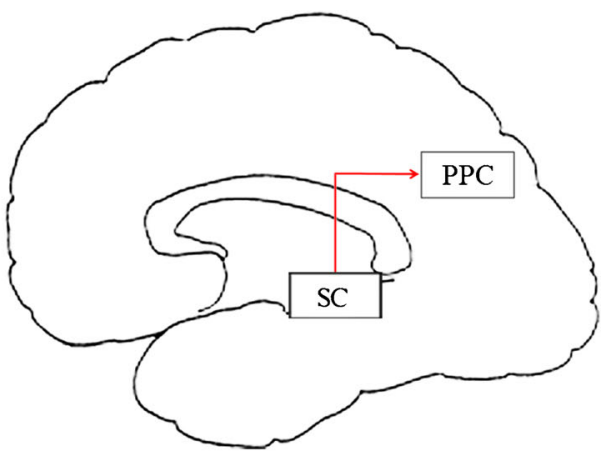

parietal cortex (PPC); the superior temporal sulcus (STS) the perirhinal cortex (PRC); and the superior colliculus (SC). Depicted primary sensory areas: primary somatosensory (S1), visual (V1), and auditory (A1) cortex. See text for details

or "multimodal integration" or "multimodal stimul*" or "audiovisual" or "audio-visual" or "visuo-auditory" or "visuotactile" or "visuo-tactile" or "tactile-visual" or "audiotactile" or "audio-tactile" or "tactile-audio" or "visual* enhanc*" or "tactile enhanc*" or "audit* enhanc*" or "somatosens* enhanc*") AND (TITLE-ABS-KEY ("hemianop*" or "visual field defect" or "visual field deficit" or "auditory disorder" or "auditory deficit" or
Fig. 2 Schematic of the literature search and article selection used by the authors to identify studies on multisensory stimulation in stroke patients
389 and 731 documents identified through Scopus and PubMed database searching respectively and 5 additional documents identified through other sources (e.g., reference lists)
104 and 347 documents excluded from the Scopus and PubMed databases respectively that were classified as a different article type than a journal article; that were classified as a review, systematic review or comment publication type; that were not conducted in humans; which had a different language than English; or of which the fulltext was not available

\section{8 documents excluded}

608 records, after duplicates removed, screened (title and abstract)

\begin{tabular}{|c|c|}
\hline $\begin{array}{l}40 \text { full-text articles assessed for } \\
\text { eligibility }\end{array}$ & $\begin{array}{l}19 \text { articles excluded: } \\
\text { - Focus on competition of }\end{array}$ \\
\hline$\downarrow$ & $\begin{array}{ll} & \text { patients with extinction (8) } \\
\text { - } & \text { No multisensory stimulation } \\
& \text { by our definition (4) } \\
\text { - } & \text { Passive stimulation (2) } \\
\text { - } & \text { Only abstract available (2) } \\
\text { - } & \text { Literature discussion (1) }\end{array}$ \\
\hline 21 studies included for review an & - No patient study (2) \\
\hline
\end{tabular}
validity evaluation 
"auditory defect" or "somatosensory disorder" or "somatosensory defect" or "somatosensory deficit" or "perceptual disorder" or "perceptual deficit" or "perceptual defect" or "neglect" or "stroke")) AND NOT (TITLE-ABSKEY ("migraine" or "synesthesia" or "synaesthesia" or "spinal cord injury" or "autism" or "aphasia" or "schizophrenia" or "dyslexia")). Documents retrieved from this initial search that were classified as an article by Scopus or as a journal article by PubMed and as being written in English were screened on their titles and abstracts. Studies were included which evaluated the effects of multisensory stimulation on patients with low- or higher-level sensory deficits caused by stroke. In all included studies at least two sensory modalities were stimulated at the exact same moment in time. The stimulation had to be passive and not active (i.e., the stimulation itself had to be independent of any action by the patient). Excluded were animal studies, studies in healthy participants (e.g., Laurienti et al. 2004; van Ee et al. 2009), reviews, and studies of which the full article was not available. Articles that focused on competition of multisensory attention in patients with extinction were excluded as well. The included articles were read completely and their references were scanned for relevant articles that might also meet criteria for inclusion. In total, 21 articles met the criteria for eligibility and were included for review and quality assessment.

\section{Quality Assessment}

The quality of the included studies was assessed based on the following eight elements (following Spreij et al. 2014): 1) randomization; 2) inclusion of control patient group; 3 ) blinding of participants; 4) blinding of researchers; 5) follow-up (i.e., subsequent examination of participants); 6) group size; 7) reporting effect sizes; and 8) reporting time post-stroke. Studies could score 1 or 0 on each element, when it was dealt with in a sufficient or insufficient way respectively. Additionally, an element was scored as 0 if it could not be inferred from the article. If these quality elements were not sufficiently dealt with, the effect of an intervention might have been either under- or overestimated (Tijssen and Assendelft 2008).

The criteria for sufficient randomization were randomized allocation to an intervention or randomized or counterbalanced presentation of the order of conditions. Inclusion of control patient group was sufficient if a control group of patients receiving either an alternative form of treatment or no intervention was included. When patients and researchers were prevented from having access to certain information that might have influenced them and thereby the results, the criteria for blinding of participants and blinding of researchers respectively were sufficiently dealt with. The criteria for sufficient follow-up were incorporation of a follow-up in the study's design and disclosure of the total number of losses-to-followup (i.e., dropouts). The element group size was scored as 1 when 10 or more patients were included in a within-subjects design or when 10 or more patients were included in each group in a between-subject design (this criterion is based on the common group size in fundamental studies in healthy participants [10-12 participants] and is used in other reviews as well [e.g., Spreij et al. 2014]). Additionally, reporting effect sizes and reporting time post-stroke were sufficiently dealt with when effect sizes and time poststroke respectively were reported. If none of the elements were sufficiently dealt with, the study would receive a total score of 0 , if all of the elements were sufficiently dealt with, the study would receive a total score of 8 . Based on the study's total score, its quality was classified as high (total score $\geq 6$ ), moderate (total score $\geq 3$ and $\leq 5$ ), or low (total score $\leq 2$ ).

\section{Results}

The specifics of the included studies are presented in Tables 1-4. First, findings in patients with low-level, perceptual deficits are addressed, including patients with visual field defects (Table 1), auditory deficits (Table 2 ) and somatosensory deficits (Table 3). Second, findings in patients with neglect are addressed (Table 4).

\section{Visual Field Defects}

Visual field defects, such as hemianopia, occur frequently after stroke, as a result of a lesion in the early visual pathway (Kandel et al. 2000). Patients with visual field defects usually fail to adequately respond to or report contralesional visual stimuli (Halligan et al. 2003), resulting in difficulties with reading, scanning scenes, and obstacle avoidance, especially on their affected side (Papageorgiou et al. 2007). Eleven studies were included that have examined direct and short-term effects (i.e., effects measured during stimulation or directly after stimulation) and/or short-term effects and longer lasting effects (i.e., effects measured not directly after stimulation) of multisensory stimulation on performance of patients with chronic and acute visual field defects. The characteristics of the studies are listed in Table 1.

Studies on the direct and short-term effects of multisensory stimulation by Frassinetti et al. (2005) and Leo et al. (2008) demonstrated that the addition of a coincident sound enhanced detection of a visual target in the affected hemifield (Frassinetti et al. 2005) and vice versa (Leo et al. 2008). In a recent study by Ten Brink et al. (2015) the addition of a coincident sound facilitated saccades to a visual target in the unaffected hemifield of all (eight) patients, but in only one patient performance in the affected hemifield was enhanced. In 


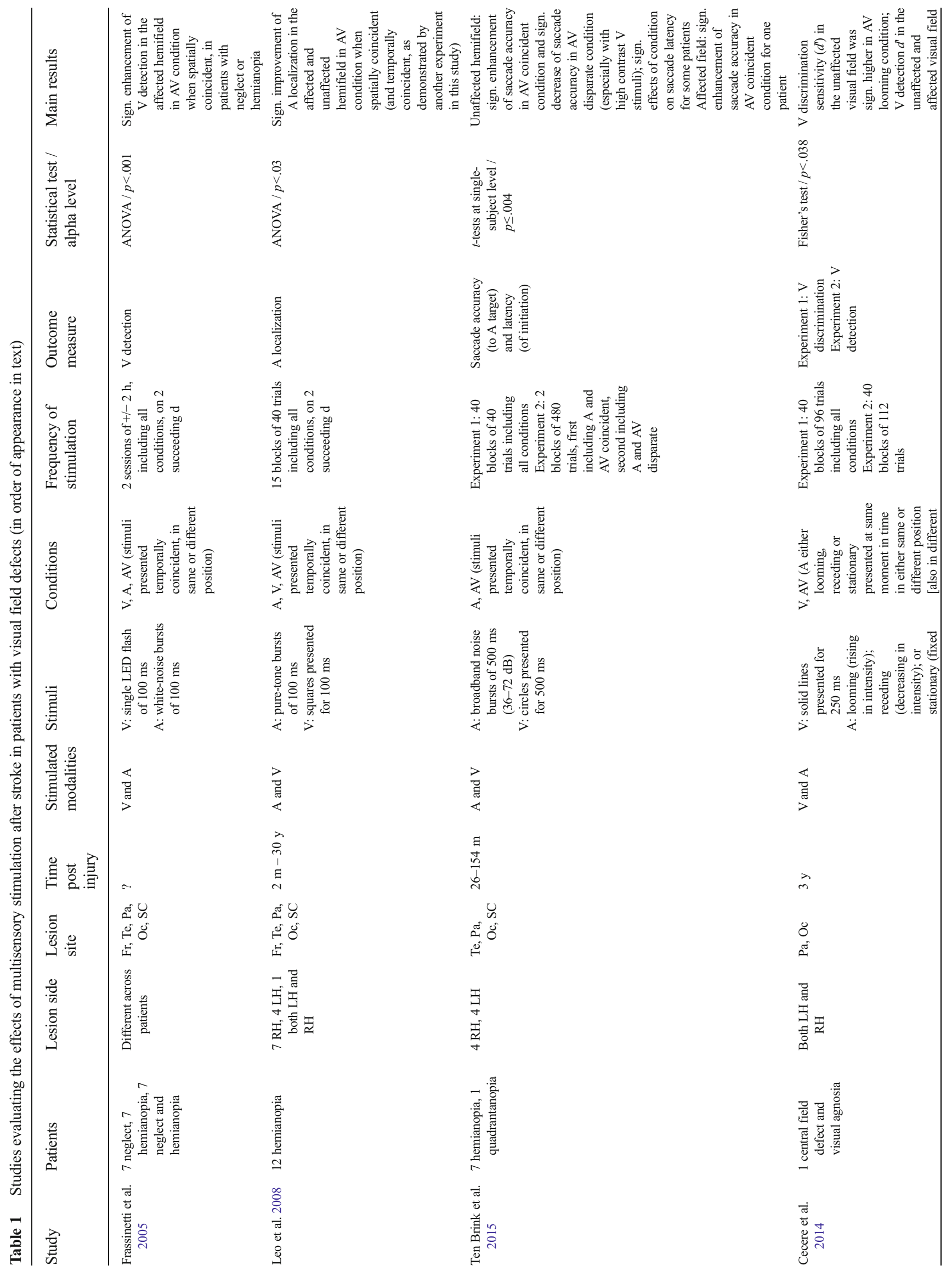




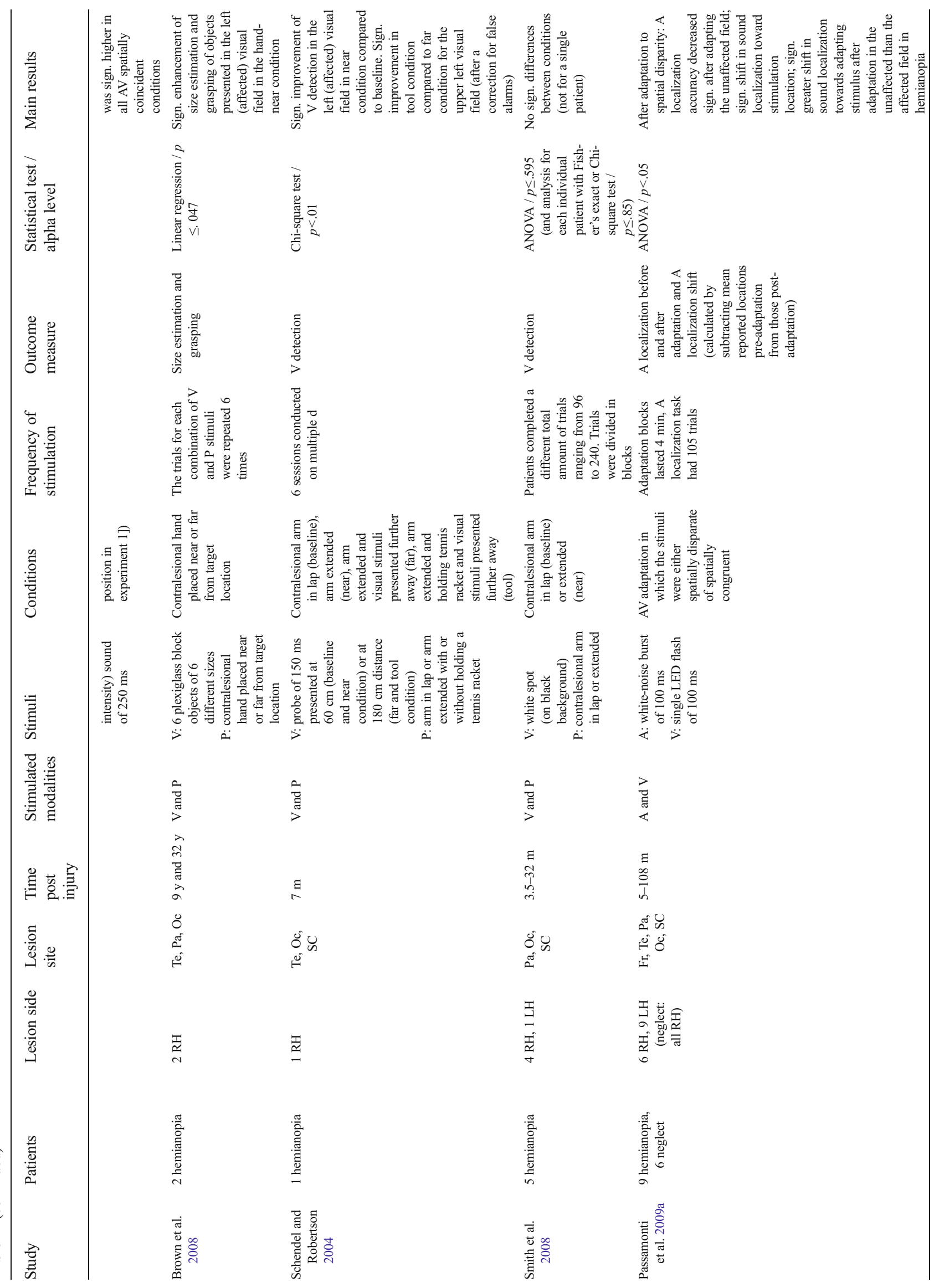




\begin{tabular}{|c|c|c|}
\hline 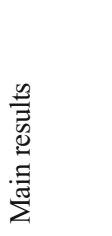 & 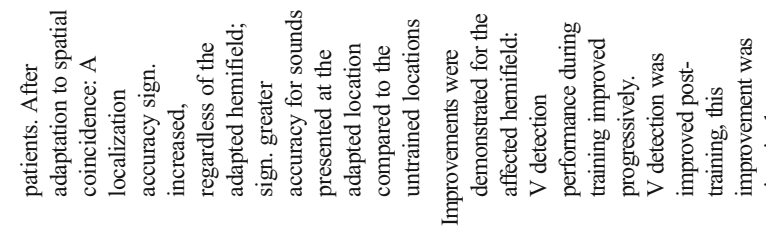 & 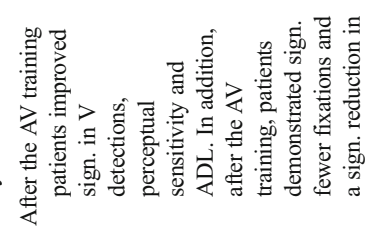 \\
\hline 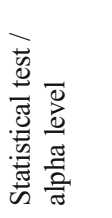 & 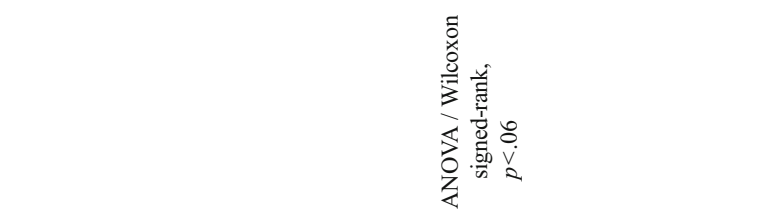 & 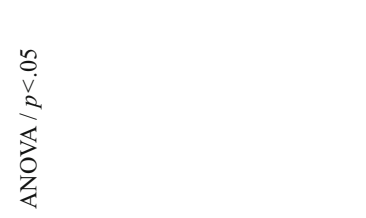 \\
\hline 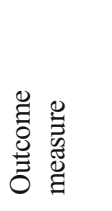 & 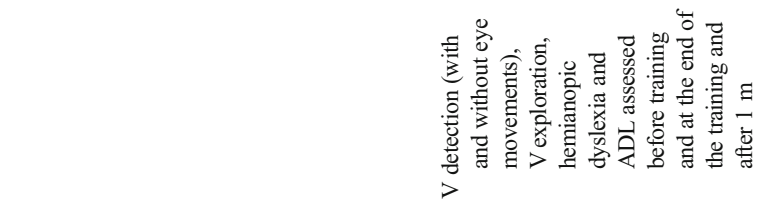 & 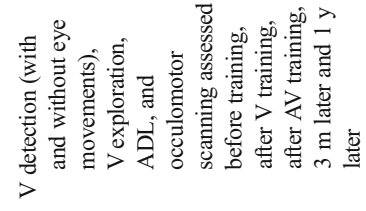 \\
\hline 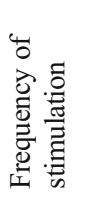 & 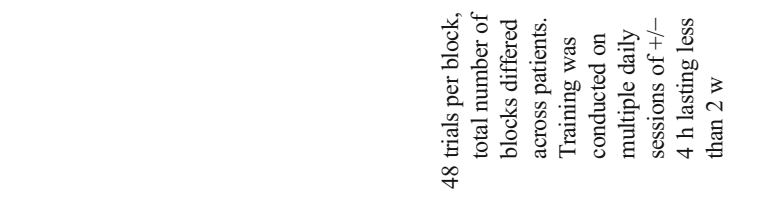 & 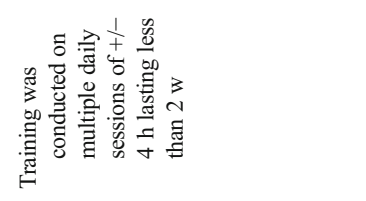 \\
\hline 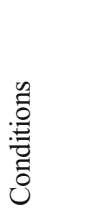 & 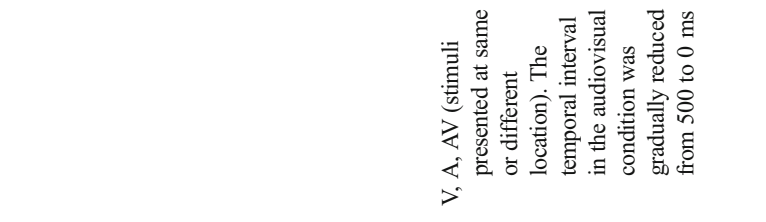 & 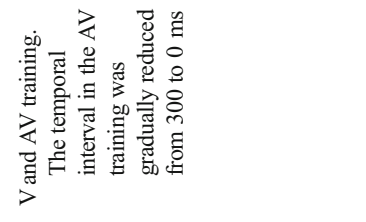 \\
\hline 言 & 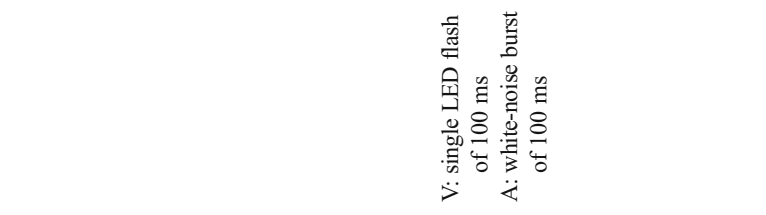 & 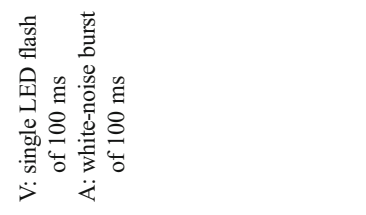 \\
\hline 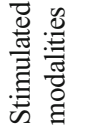 & 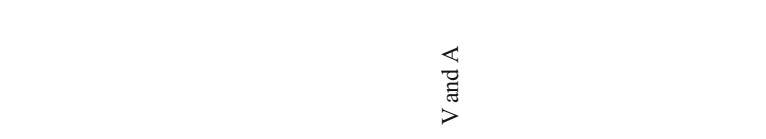 & 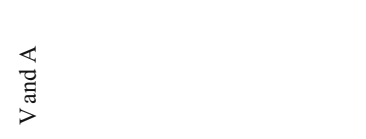 \\
\hline 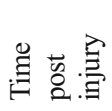 & $\underset{\sim}{\vec{d}}$ & $\begin{array}{l}0 \\
1 \\
1 \\
n\end{array}$ \\
\hline 造 & 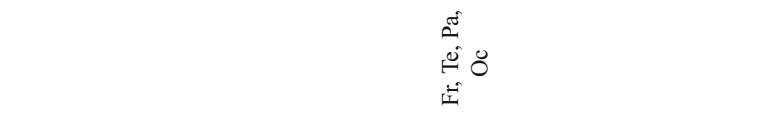 & 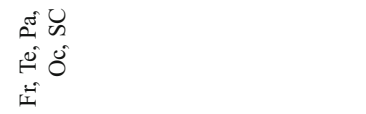 \\
\hline 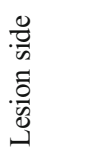 & 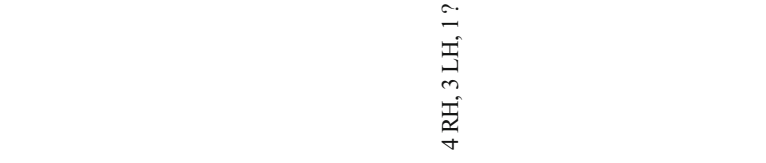 & \\
\hline 䓌 & 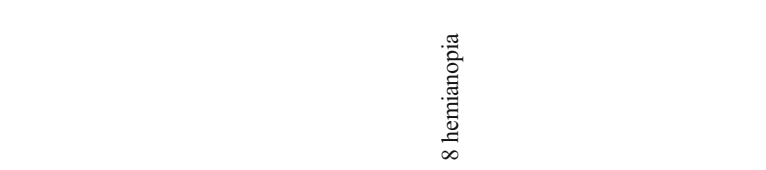 & 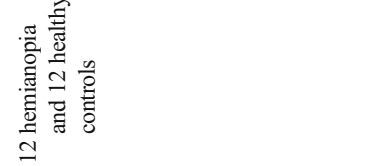 \\
\hline $\begin{array}{l}\text { 胥 } \\
\text { 离 }\end{array}$ & 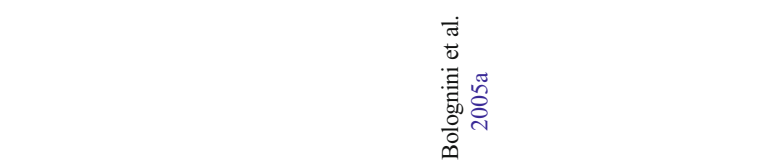 & 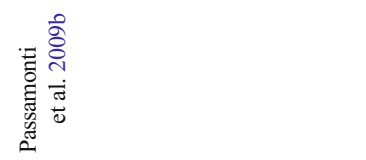 \\
\hline
\end{tabular}




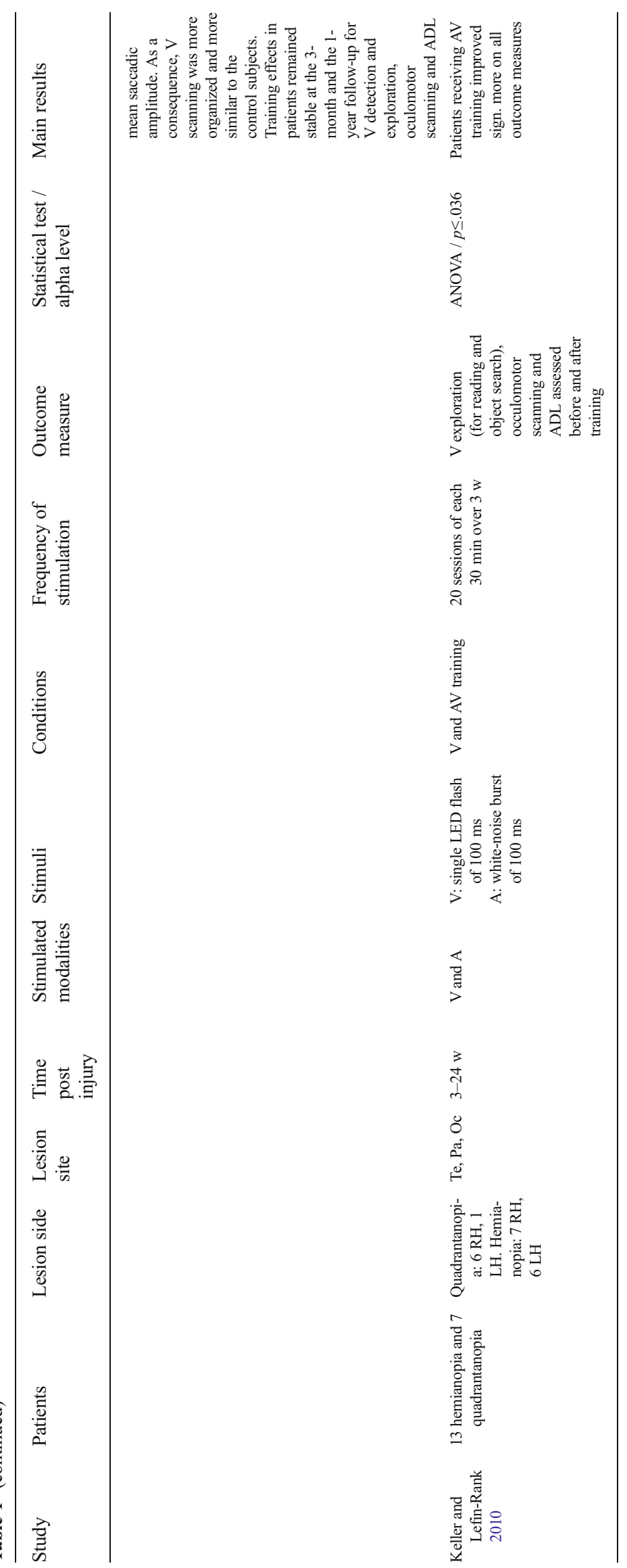

黑 Springer 

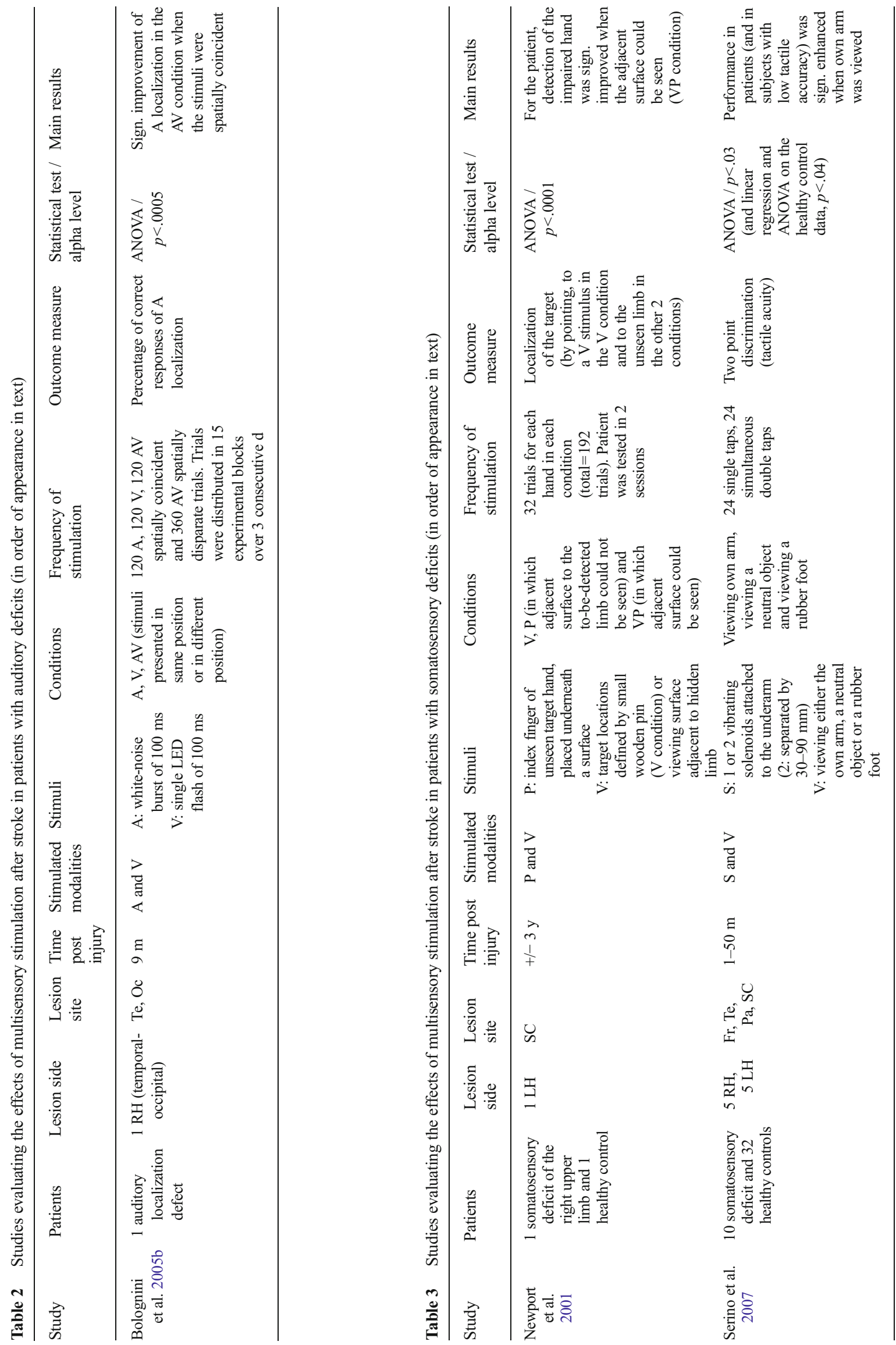


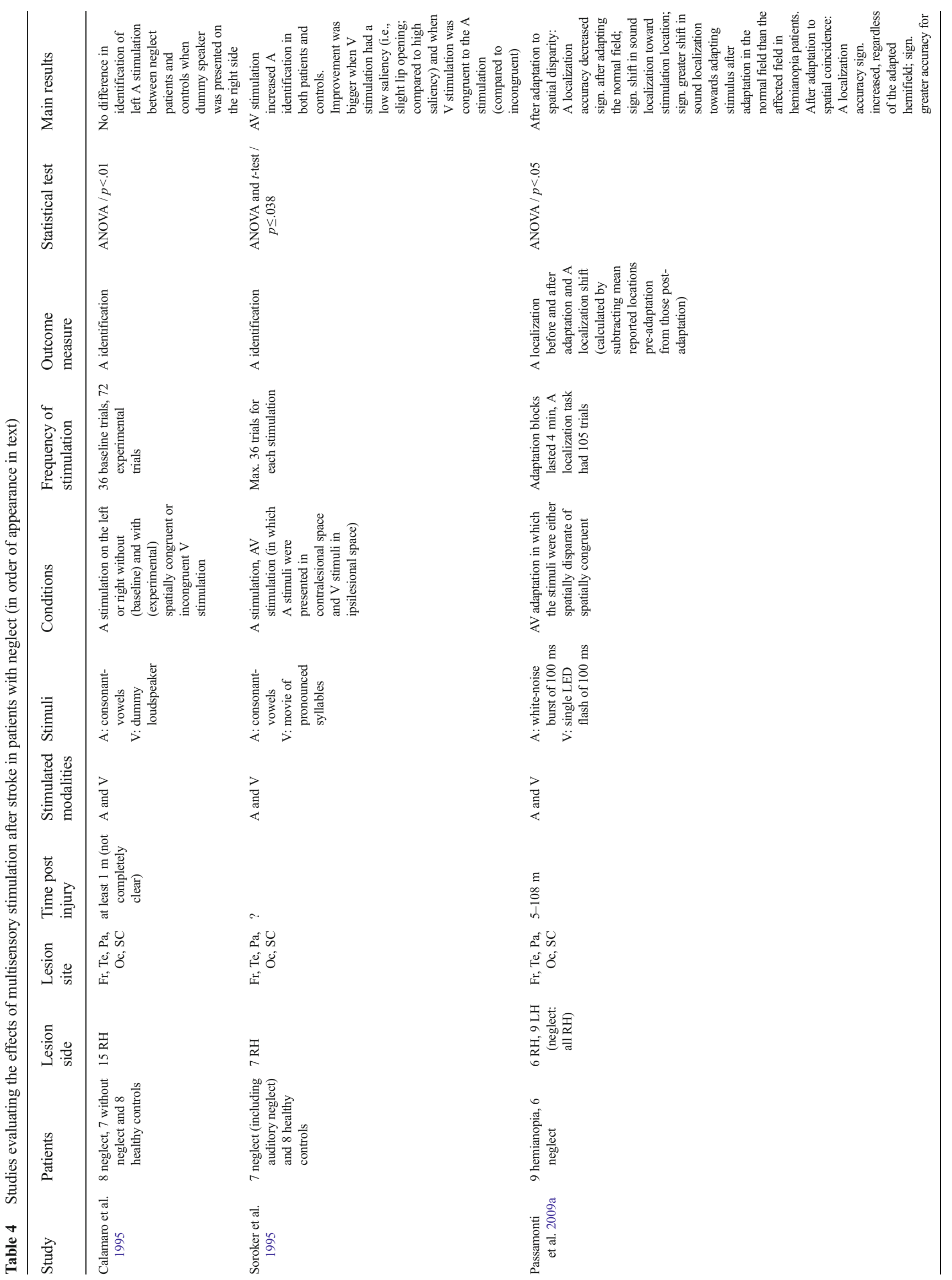




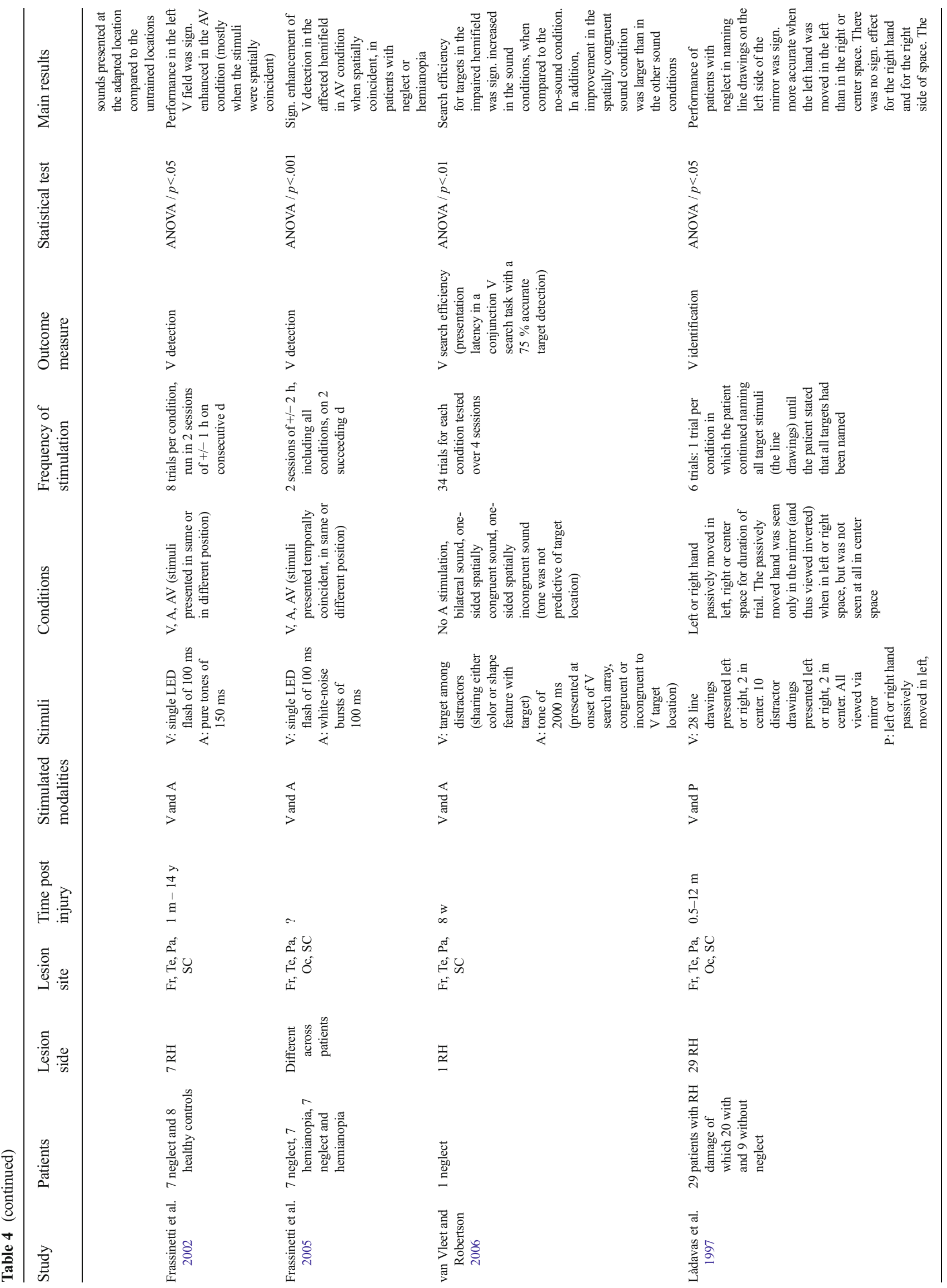




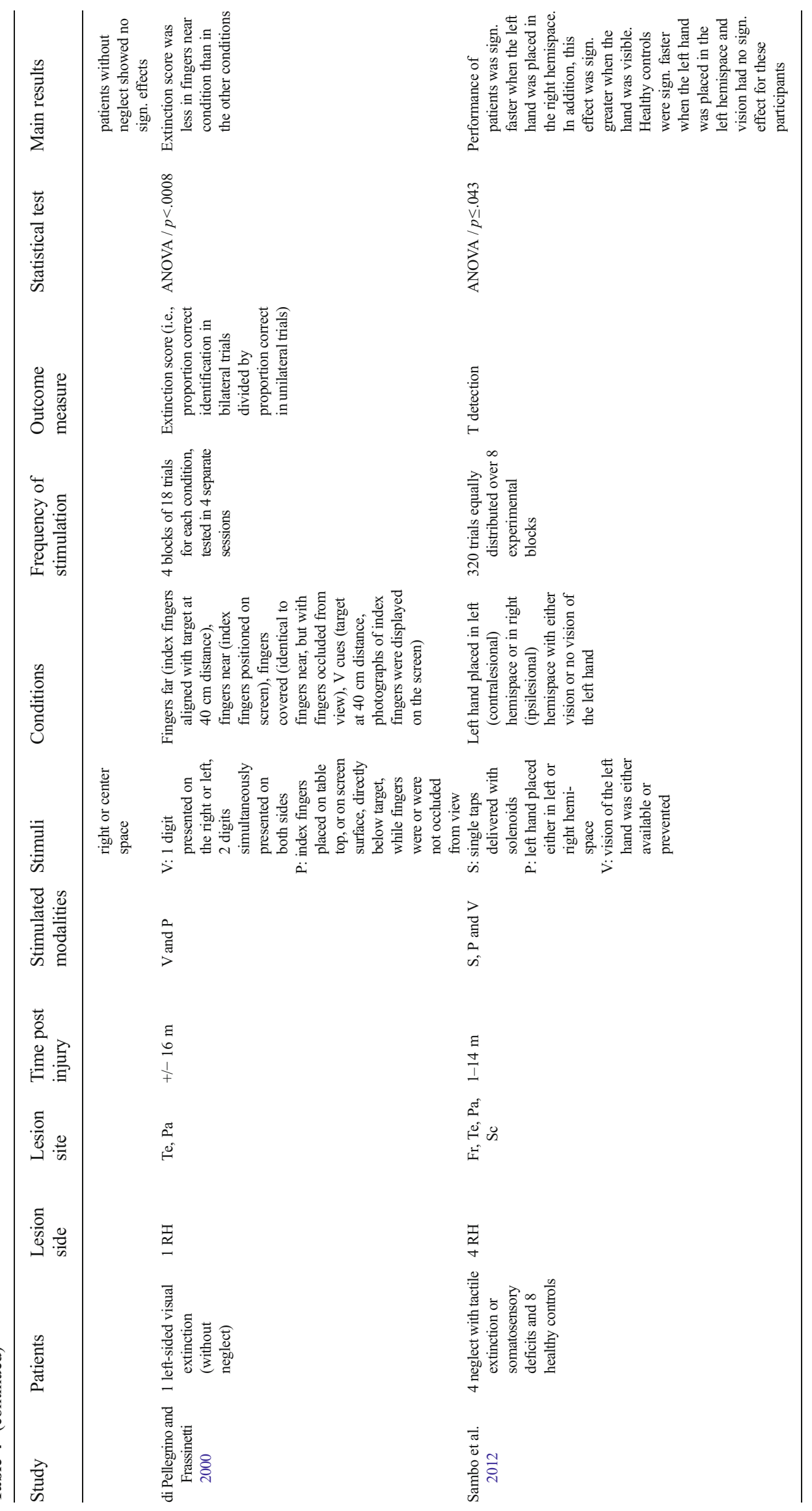


addition, Cecere et al. (2014) presented a patient with a complete loss of central vision and visual agnosia with different types of sounds (looming, receding, and stationary) while examining his visual discrimination and detection abilities. Visual discrimination in the unaffected, but not affected, visual field was enhanced by the addition of a coincident looming sound. Visual detection was enhanced by the addition of all types of coincident sounds in both the unaffected and affected field.

Brown et al. (2008) demonstrated that proprioceptive information provided by placing patients' left hand near objects improved target size processing of these objects in the hemianopic field. Likewise, in a single case study by Schendel and Robertson (2004), visual detection in the affected hemifield improved when the patient's contralesional arm was extended into the affected field, but only for visual stimuli near the extended hand. However, these findings could not be replicated in a sample of five patients in an otherwise largely similar study of Smith et al. (2008).

Apart from the direct and short-term improvements, longer lasting effects have also been reported. Passamonti et al. (2009a) found that auditory localization improved after four minutes of adaptation to spatially congruent audiovisual stimulation, especially at the location where audiovisual stimuli were presented. Bolognini et al. (2005a) presented patients with unisensory and multisensory trials in daily sessions of about four hours for nearly two weeks. Patients improved in visual detection, visual exploration and in different tasks of daily life (relating to visual impairments), and these improvements were stable at the follow-up after one month. This study, however, did not rule out that a similar improvement might have been obtained by only using unisensory (visual) stimulation, as all the different conditions were incorporated in the sessions. To overcome this confound, Passamonti et al. (2009b) incorporated an unisensory, visual training as well as an audio-visual training and showed that audiovisual training improved visual detection and exploration, oculomotor scanning and activities of daily life, whereas the visual training did not. These effects remained stable at a three-month follow-up and a one-year follow-up.

Keller and Lefin-Rank (2010) examined the effects of audiovisual stimulation in patients in the subacute stage after brain damage. Patients received either audiovisual training or visual training. The audiovisual training resulted in a larger improvement in visual exploration compared to the visual training. In addition, only patients that had received audiovisual training showed near normal daily living activities (relating to visual impairments) after the training of three weeks. Yet, the role of spontaneous recovery in these findings is not clear, as there was no group of patients receiving no training at all.

\section{Auditory Localization Deficits}

Only a single study examining the effects of multisensory stimulation on specific auditory deficits after stroke was included (Table 2). Bolognini et al. (2005b) investigated whether a temporally congruent visual stimulus improved the localization of an auditory stimulus in a patient with a selective deficit of auditory spatial localization, yet intact detection, in the whole auditory field. Auditory localization improved, but only when the visual stimulus was spatially congruent.

\section{Somatosensory Deficits}

Impaired somatosensory function has negative effects on exploration of the environment, spontaneous use of hands, precision grip and object manipulation. Additionally, it has negative effects on rehabilitation outcomes, such as personal safety, functional outcome and quality of life (Carey 1995; Carey and Matyas 2011). Two studies on the effect of multisensory stimulation in patients with somatosensory deficits were included (Table 3 ). These studies examined the effect of viewing either a relevant body part or the surface adjacent to it. When a relevant body part or its adjacent surface is viewed, stimulation might be provided by descending modulatory inputs from visual body representation areas which could aid in the reorganization of damaged brain areas in somatosensory deficits.

Newport et al. (2001) investigated the effect of combining vision and proprioception in a patient with a unilateral somatosensory impairment of the right upper limb, including right tactile extinction (i.e., the failure to report a contralesional stimulus only when it is delivered together with a concurrent ipsilesional stimulus [Gallace and Spence 2008]). When the patient could view the surface adjacent to her hidden to-be-localized limb, detection of the impaired limb improved compared to when she was blindfolded. In addition, a single case study by Serino et al. (2007) indicated that during invisible stimulation of the upper limb, tactile thresholds were improved when the own upper limb was viewed compared to viewing a rubber foot or a neutral object.

\section{Neglect}

Patients with unilateral spatial neglect suffer from impaired explicit spatial processing (i.e., reporting and/or exploring) of stimuli presented in the affected contralesional space (Gallace and Spence 2008; Ting et al. 2011). Additionally, patients with neglect can have a disrupted mental representation of space, which is generally shifted to the ipsilesional space and therefore underrepresents the contralesional space (Mesulam 1999; Zamarian et al. 2007). Effective rehabilitation of neglect is of utmost importance as the disorder is associated with poorer cognitive and motor recovery and poorer outcomes on ADL (activities of daily living; Heilman et al. 2000; Buxbaum et al. 2004; Nijboer et al. 2013, 2014). Neglect can occur in all perceptual domains (Kinsbourne 1993) and in different regions of space (Aimola et al. 2012; Van der Stoep et al. 2013). Extinction often occurs in patients 
with neglect, however, double dissociations have been reported (Pavlovskaya et al. 2007). Nine studies were included that have examined the effects of multisensory stimulation on performance of patients with neglect and/or extinction. The characteristics of these studies are listed in Table 4.

Two early studies of Calamaro et al. (1995) and Soroker et al. (1995) demonstrated that identification of auditory stimuli in the impaired hemispace of patients with neglect was enhanced with additional visual stimulation in the intact hemispace. Passamonti et al. (2009a) demonstrated that auditory localization in patients with neglect was improved after four minutes of adaptation to spatially congruent, but not spatially incongruent, audiovisual stimuli, especially at the adapted location.

Furthermore, as demonstrated in the studies of Frassinetti et al. $(2002,2005)$, detection of a visual stimulus improved on the contralesional side when a spatially congruent sound was presented simultaneously. van Vleet and Robertson (2006) demonstrated that target detection improved in the impaired hemifield when a tone was presented at the onset of the search display in a location congruent to the target location.

Làdavas et al. (1997) and di Pellegrino and Frassinetti (2000) examined whether position of the hands could modulate visual neglect or visual extinction respectively. In the first study, patients with neglect viewed visual targets and distractors via a mirror and were more accurate in identifying targets on the left side of the mirror when the left hand was passively moved on the left side of space (Làdavas et al. 1997). In the di Pellegrino and Frassinetti study (2000) a patient's visual extinction for left targets was reduced when the patient's fingers were positioned below the visual targets. The left-sided extinction was not reduced when the patient's fingers were occluded from view.

Furthermore, Sambo et al. (2012) examined the effect of proprioceptive and visual information on processing of tactile stimuli in patients with both neglect and left tactile extinction or somatosensory deficits. Processing of left invisible tactile stimulation was enhanced when patients placed their left hand in the ipsilesional, 'intact', hemispace compared to when they placed the hand in the contralesional, 'impaired', hemispace, especially when patients were able to see the hand.

\section{Quality Assessment}

In the section above the included studies on multisensory stimulation after stroke were discussed. Overall, twenty out of twenty-one studies reported a beneficial effect of multisensory stimulation in improving sensory deficits. In this section we assess the discussed studies on 1) randomization; 2) inclusion of control patient group; 3) blinding of participants; 4) blinding of researchers; 5) follow-up; 6) group size; 7) reporting effect sizes; and 8) reporting time post-stroke (Table 5).

\section{Study Characteristics}

Of the 21 discussed studies, only 1 (Keller and Lefin-Rank 2010) consisted of a between-subjects design. The other studies were within-subjects designs, 6 (di Pellegrino and Frassinetti 2000; Newport et al. 2001; Schendel and Robertson 2004; Bolognini et al. 2005b; van Vleet and Robertson 2006; Cecere et al. 2014) of which were single case studies. On a 8-point scale (representing the 8 elements on which the articles were assessed, with 8 indicating the highest and 0 the lowest possible score), the average total score for all studies was $2(S D=1.1$, range $0-4)$. Based on the total scores, 6 studies were of moderate quality ( 4 studies had a total score of 3 , and 2 studies had a total score of 4) and fifteen were of low quality ( 2 studies had a total score of 0,4 studies had a total score of 1 , and 9 studies had a total score of 2). The average score for studies on visual field defects was 2 (11 studies), on auditory deficits 2 (1 study), on somatosensory deficits 2.5 ( 2 studies), and on neglect 2 (9 studies). Of the 21 studies, only a single study (Smith et al. 2008), which included patients with hemianopia, did not report beneficial effects of multisensory stimulation, this study was assessed with a total score of 2 .

All discussed studies included detection, localization, exploration, discrimination and/or identification outcome measures in their design. Only 3 of the 21 studies discussed (all on hemianopia; Bolognini et al. 2005a; Passamonti et al. 2009b; Keller and Lefin-Rank 2010) included ADL outcome measures in their design, rendering the discussed studies' foci mostly experimental.

\section{Randomization and Inclusion of Control Group}

Ideally, studies investigating the effect of an intervention should have a group of patients receiving an intervention and a control group of patients, either not receiving any intervention or receiving a 'control intervention' (Higgins et al. 2011). Only a single study (Keller and Lefin-Rank 2010) had incorporated a control patient group: two randomly allocated groups of patients with hemianopia or quadrantanopia received either multisensory or unisensory training. The study demonstrated that patients benefited more from multisensory training than unisensory training.

In all the other discussed studies, each patient participated in at least two different conditions, namely an experimental condition (with multisensory stimulation) and a control condition (without multisensory stimulation). In this way, effects of multisensory stimulation could be compared within patients. Twelve of twenty within-subjects design studies (Làdavas et al. 1997; di Pellegrino and Frassinetti 2000; Newport et al. 2001; Frassinetti et al. 2002; Schendel and Robertson 2004; Bolognini et al. 2005b; Frassinetti et al. 2005; van Vleet and Robertson 2006; Serino et al. 2007; 
Table 5 Scores of the quality assessment of the discussed studies, based on eight elements ${ }^{\text {a }}$

\begin{tabular}{|c|c|c|c|c|c|c|c|c|c|c|}
\hline Study & $\begin{array}{l}\text { Randomization } \\
\text { of intervention } \\
\text { or conditions }\end{array}$ & $\begin{array}{l}\text { Inclusion of } \\
\text { control patient } \\
\text { group }\end{array}$ & $\begin{array}{l}\text { Blinding of } \\
\text { participants }\end{array}$ & $\begin{array}{l}\text { Blinding of } \\
\text { researchers }\end{array}$ & Follow-up & $\begin{array}{l}\text { Group } \\
\text { size }\end{array}$ & $\begin{array}{l}\text { Reporting } \\
\text { effect } \\
\text { sizes }\end{array}$ & $\begin{array}{l}\text { Reporting } \\
\text { time } \\
\text { post-stroke }\end{array}$ & Total & Quality \\
\hline Frassinetti et al. 2005 & 1 & 0 & 0 & 0 & 0 & 0 & 0 & 0 & 1 & low \\
\hline Leo et al. 2008 & 0 & 0 & 0 & 0 & 0 & 1 & 0 & 1 & 2 & low \\
\hline Ten Brink et al. 2015 & 0 & 0 & 0 & 0 & 0 & 0 & 0 & 1 & 1 & low \\
\hline Cecere et al. 2014 & 0 & 0 & 0 & 0 & 0 & 0 & 0 & 1 & 1 & low \\
\hline Brown et al. 2008 & 1 & 0 & 0 & 0 & 0 & 0 & 0 & 1 & 2 & low \\
\hline $\begin{array}{l}\text { Schendel and Robertson } \\
2004\end{array}$ & 1 & 0 & 0 & 0 & 0 & 0 & 0 & 1 & 2 & low \\
\hline Smith et al. 2008 & 1 & 0 & 0 & 0 & 0 & 0 & 0 & 1 & 2 & low \\
\hline Passamonti et al. 2009a & 0 & 0 & 0 & 0 & 0 & 0 & 0 & 1 & 1 & low \\
\hline Bolognini et al. 2005a & 0 & 0 & 0 & 0 & 1 & 0 & 0 & 1 & 2 & low \\
\hline Passamonti et al. 2009b & 0 & 0 & 0 & 1 & 1 & 1 & 0 & 1 & 4 & moderate \\
\hline $\begin{array}{l}\text { Keller and Lefin-Rank } \\
2010\end{array}$ & 1 & 1 & 0 & 0 & 0 & 1 & 0 & 1 & 4 & moderate \\
\hline Bolognini et al. 2005b & 1 & 0 & 0 & 0 & 0 & 0 & 0 & 1 & 2 & low \\
\hline Newport et al. 2001 & 1 & 0 & 0 & 0 & 0 & 0 & 0 & 1 & 2 & low \\
\hline Serino et al. 2007 & 1 & 0 & 0 & 0 & 0 & 1 & 0 & 1 & 3 & moderate \\
\hline Calamaro et al. 1995 & 0 & 0 & 0 & 0 & 0 & 0 & 0 & 0 & 0 & low \\
\hline Soroker et al. 1995 & 0 & 0 & 0 & 0 & 0 & 0 & 0 & 0 & 0 & low \\
\hline Frassinetti et al. 2002 & 1 & 0 & 0 & 0 & 0 & 0 & 0 & 1 & 2 & low \\
\hline $\begin{array}{l}\text { van Vleet and Robertson } \\
2006\end{array}$ & 1 & 0 & 0 & 1 & 0 & 0 & 0 & 1 & 3 & moderate \\
\hline Làdavas et al. 1997 & 1 & 0 & 0 & 0 & 0 & 1 & 0 & 1 & 3 & moderate \\
\hline $\begin{array}{l}\text { di Pellegrino and Frassinetti } \\
2000\end{array}$ & 1 & 0 & 0 & 0 & 0 & 0 & 0 & 1 & 2 & low \\
\hline Sambo et al. 2012 & 1 & 0 & 0 & 0 & 0 & 0 & 1 & 1 & 3 & moderate \\
\hline
\end{tabular}

a $0=$ element was dealt with insufficiently; $1=$ element was dealt with sufficiently

Brown et al. 2008; Smith et al. 2008; Sambo et al. 2012) reported that they had randomized or counterbalanced the different conditions, in the other studies this was not reported.

To allow for monitoring of 'practice effects' and verification of improvement of performance toward normal levels, a control group of healthy participants is very useful. Only six of the studies incorporated a control group of healthy subjects (Calamaro et al. 1995; Soroker et al. 1995; Newport et al. 2001; Passamonti et al. 2009b; Serino et al. 2007; Sambo et al. 2012) but in one study (Passamonti et al. 2009b) the healthy control group did not receive the exact experimental training as the patients. These studies demonstrated that the effect of multisensory stimulation was larger in patients compared to healthy controls (Newport et al. 2001; Passamonti et al. 2009b; Sambo et al. 2012) or that patients could perform on the level of healthy controls when multisensory information was presented (Calamaro et al. 1995). Moreover, these studies demonstrated that multisensory stimulation could lead to improvements both in patients and healthy controls (Soroker et al. 1995) or in patients and healthy controls with a low sensory acuity only (Serino et al. 2007).

\section{Blinding of Participants and Researchers}

Only three of the twenty-one studies reported that researchers were blinded for one important aspect (van Vleet and Robertson 2006; Passamonti et al. 2009b; Keller and Lefin-Rank 2010). Yet, in one of these studies (Keller and Lefin-Rank 2010) not all researchers were blinded. The two studies that dealt with blinding of researchers sufficiently demonstrated that multisensory stimulation could be beneficial in patients with hemianopia (Passamonti et al. 2009b) or neglect (van Vleet and Robertson 2006). None of the studies reported that patients were blinded. As a direct result of the design chosen, blinding is more difficult when each patient is tested in all conditions and when the difference between the conditions is clear (for example: performing a task with or without a distinctive sound), which was the case in most of the discussed studies.

\section{Follow-Up}

Sufficient follow-up to the examination is of great importance to assess the effects of the intervention over a prolonged 
period of time. Only two of the twenty-one studies discussed (Bolognini et al. 2005a; Passamonti et al. 2009b) incorporated a follow-up in their design (with no losses-to-follow-up). They found that patients with hemianopia could improve in visual detection and (oculomotor) exploration in the impaired field and in different tasks of daily life with multisensory stimulation. These beneficial effects were stable at a one month (Bolognini et al. 2005a) and at a one year (Passamonti et al. 2009b) followup. With respect to the other studies on low-level sensory impairment and neglect, no follow-up results were reported.

\section{Group Size}

Studies with small groups often have large confidence intervals and are less able to detect clinically relevant effects statistically. Group sizes in the discussed studies were relatively small. The average group size in the discussed studies was $6.36(S D=4.81$, range $1-20)$. The largest group had 20 patients (Làdavas et al. 1997), 9 studies (including 6 case studies) had 1 to 5 patients, and 11 studies had 7 to 12 patients. The average group size for studies on visual field defects was 6.7 (11 studies), on auditory deficits 1 (1 study), on somatosensory deficits 5.5 (2 studies), on neglect 6.9 (9 studies). One of the twenty-one discussed studies (Smith et al. 2008) did not find a difference between unisensory and multisensory stimulation in patients with hemianopia; this study included 5 patients.

\section{Reporting Effect Sizes and Time Post-Stroke}

An important factor that should be reported is the effect size to determine the strength of the statistically significant results. Yet, only 1 of the 21 studies discussed (Sambo et al. 2012) reported effect sizes. This study found that multisensory stimulation enhanced tactile detection, with an effect size $(\eta 2)$ ranging from 0.46 to 0.76 , which is considered as a large effect size (Cohen 1988). Another important factor that should be mentioned is the time post-stroke onset to verify response to treatment in different phases of recovery. Three of the studies discussed (Frassinetti et al. 2005; Calamaro et al. 1995; Soroker et al. 1995) did not report the time post-stroke of their included patients. Overall, studies demonstrating beneficial effects of multisensory stimulation included patients between 0.5 months to 32 years post stroke, effects in the early acute phase were not reported.

\section{Discussion}

This review has attempted to assess and integrate evidence for the effectiveness of multisensory stimulation as a possible rehabilitation method for functional recovery for patients with low- or higher-level sensory deficits after stroke. We hypothesized that multisensory stimulation has the potential to be beneficial for these groups of patients, as information from a normally functioning sensory modality might aid the processing of information from the impaired sensory modality. Twenty of the twenty-one included studies demonstrated beneficial effects of multisensory stimulation on patients with low- and/or higher-level sensory deficits. These studies demonstrated that detection, localization, exploration, discrimination, identification, and even several activities of daily living could be enhanced by multisensory stimulation in both patients with low- and patients with higher-level sensory impairments. Notwithstanding these beneficial effects, our quality assessment classified 6 studies as being of moderate and 15 studies as being of low quality. Most studies employed a within-subjects design with small groups and more than a third of these studies did not report taking into account randomization/counterbalancing of the different conditions. In addition, none of the studies reported blinding all important aspects, only two studies incorporated a follow-up in their design, three studies did not report time post-stroke, and only one study reported effect sizes. Most importantly, the discussed studies' foci were mostly experimental (focusing on tasks such as signal detection or signal localization); only three studies measured the effect of multisensory stimulation on ADL-measures. Therefore, at present, none of the studies on multisensory stimulation after stroke are adequate to give a proper evaluation of the effectiveness of the method as an intervention. We believe that now is the time to take this line of research to the next level and set-up well-designed randomized controlled trials (RCTs), in which the important discussed quality elements are taken into account and in which ADLmeasures are included, to examine the effectiveness of multisensory stimulation as an intervention after stroke.

\section{Starting Points for Future Research}

Regarding the type of stimulation, a good starting point for an RCT might be audiovisual stimulation, as most included studies (13 out of 21) focused on this type of stimulation and this type of stimulation is well controllable. Hemianopia might then be a suitable candidate to target first, as most studies focused on patients with hemianopia (10 out of 21), this impairment occurs relatively frequently after stroke, and the implicated visual neural networks are well-documented (e.g., Kandel et al. 2000). Yet, recent research demonstrated that visual spatial localization can be distorted in patients with hemianopia (Fortenbaugh et al. 2015), which can complicate any spatial multisensory approach to rehabilitation. It is therefore essential that future studies in patients with hemianopia include appropriate baseline conditions to measure also these distortions. In this way, future studies can control for the influence of any comorbid (visual) disorders on effects of multisensory stimulation. After establishing an 
effective protocol for patients with hemianopia, the effectiveness of the protocol can be examined for other disorders as well. Expanding collaborations between fundamental and clinical researchers might ensure that potentially interesting techniques can be studied in clinical populations soon after fundamental studies demonstrate positive effects of these techniques.

\section{Potential Mechanisms for Rehabilitation}

When considering multisensory stimulation as an intervention, it is of importance to determine if improvements might result from recovery or compensatory responses. Recovery is the reappearance of pre-stroke function and is characterized by restitution or repair of the functionality of damaged neural structures (Levin et al. 2009). Compensation, on the other hand, is the reduction of the disparity between an impaired function and the environmental demands characterized by activation in alternative brain areas that are not normally activated in controls (Levin et al. 2009).

While most studies demonstrated short-term beneficial effects of multisensory stimulation, two studies (Bolognini et al. 2005a; Passamonti et al. 2009b) provided evidence that effects of multisensory 'training' (of less than two weeks) can persist for a longer period of time (up to one year). The underlying mechanisms of these long-term effects, which are especially interesting from a rehabilitation point of view, are not yet established. To speculate, long-term effects might mainly result from restoration, as multisensory stimulation might recruit and, in turn, strengthen residual (sensory) pathways in the brain and thereby might restore sensory performance and function (Jiang et al. 2015). Direct effects, on the other hand, might mainly result from passive compensation (e.g., multisensory stimuli surpassing the attention threshold, thereby 'normalizing' sensory performance and function), as neurobiological recovery is known to require more time to complete (Teasell and Hussein 2014). Possibly, direct effects might mostly reflect enhanced attention to the stimulated location. It might be especially effective to target restoration in the first three months post-stroke, as in this period it is most likely that neurobiological recovery will take place (Kwakkel et al. 2004; Levin et al. 2009; Nijboer et al. 2013). Future studies should aim at identifying an optimal timing at which multisensory stimulation would be most effective.

Restoration of sensory performance and function might also lead to improvements on ADL (see Bolognini et al. 2005a; Passamonti et al. 2009b; Keller and Lefin-Rank 2010). Future studies should therefore examine the effects of restoration on cognitive (such as attention and memory) outcome measures, and to what extent the effects of multisensory stimulation are transferred (on the long-term). This could for example be achieved by assessing these outcomes before and after (with multiple follow-up measurements) multisensory 'training'.
When considering multisensory stimulation as an intervention in future research, it is also essential to determine the optimal frequency, duration and intensity of multisensory stimulation and which patients benefit from multisensory stimulation and/or which brain regions need to be intact in order to benefit from multisensory stimulation. The discussed studies included patients mainly based on behavioral criteria and were not consistent in reporting their etiology (e.g., hemorrhagic or ischemic stroke), another factor that may well codetermine the effects of multisensory stimulation in rehabilitation. Future studies would benefit from standardized tasks and outcome measures. This could possibly contribute to establishing the degree of clinical relevance for observed outcome effects, quantified by, for example, the minimal clinically important difference (MCID). At the moment, scientific acceptance for the MCID is not yet achieved (Gatchel et al. 2010; King 2011). Establishing a quantification of clinical relevance would be valuable, as effects should not only have statistical significance, but also significance in improving the patients' lives.

\section{Study Limitations}

A limitation of the current review might be the incomplete retrieval of studies as the retrieval was limited to the selected keywords and databases. The selected inclusion and exclusion criteria resulted in inclusion of studies with a specific focus, while excluding studies on related subjects. Most noteworthy, this review selected studies on passive multisensory stimulation in sensory recovery after stroke. Obviously, stimulating motor recovery to prevent functional loss is very important as well (Nudo et al. 1996). Additionally, the type of studies included might only have been reported after a positive result. This results in a positive publication bias, which might have led to an underrepresentation of studies showing no beneficial effects of multisensory stimulation. A limitation regarding the included studies concerns the studies' foci, which were mainly experimental. This resulted in an insufficient score on our quality assessment and restricts any conclusion on the clinical relevance of multisensory stimulation. Yet, the lack of studies focused on clinical application emphasizes the need for the implementation of proper RCTs.

\section{Conclusion}

In conclusion, in recent years there has been a tremendous increase in fundamental cognitive neuroscience research on multisensory integration. In addition, a number of studies have reported promising results of multisensory stimulation in low-level as well as higher-level sensory impairments after stroke. Yet, as the quality of these studies was insufficient, at this moment it cannot be concluded that multisensory stimulation can be successfully applied as an effective intervention. 
It would be a valuable next step to continue this line of research with well-designed randomized controlled trials to examine whether and how multisensory stimulation can aid recovery after stroke.

\section{Compliance with Ethical Standards}

Conflict Interests The authors declared no potential conflicts of interest with respect to the research, authorship, and/or publication of this article.

Financial Disclosure Tanja C. W. Nijboer was supported by Netherlands Organization for Scientific Research grant \#451-10-013. Raymond van Ee was supported by a grant from the Flemish Methusalem program (METH/08/02 assigned to J. Wagemans), the EU HealthPac grant (assigned to J.A. van Opstal), and the Flanders Scientific Organization.

The authors received no financial support for the research, authorship, and/or publication of this article.

Open Access This article is distributed under the terms of the Creative Commons Attribution 4.0 International License (http:// creativecommons.org/licenses/by/4.0/), which permits unrestricted use, distribution, and reproduction in any medium, provided you give appropriate credit to the original author(s) and the source, provide a link to the Creative Commons license, and indicate if changes were made.

\section{References}

Aimola, L., Schindler, I., Simone, A. M., \& Venneri, A. (2012). Near and far space neglect: task sensitivity and anatomical substrates. Neuropsychologia, 50(6), 1115-23.

Allman, B. L., Keniston, L. P., \& Meredith, M. A. (2009). Not just for bimodal neurons anymore: the contribution of unimodal neurons to cortical multisensory processing. Brain Topography, 21(3-4), 157-67.

Amedi, A., Malach, R., Hendler, T., Peled, S., \& Zohary, E. (2001). Visuo-haptic object-related activation in the ventral visual pathway. Nature Neuroscience, 4(3), 324-30.

Amedi, A., Jacobson, G., Hendler, T., Malach, R., \& Zohary, E. (2002). Convergence of visual and tactile shape processing in the human lateral occipital complex. Cerebral Cortex, 12(11), 1202-12.

Beauchamp, M. S., Yasar, N. E., Frye, R. E., \& Ro, T. (2008). Touch, sound and vision in human superior temporal sulcus. NeuroImage, 41(3), 1011-20.

Bolognini, N., Rasi, F., Coccia, M., \& Làdavas, E. (2005a). Visual search improvement in hemianopic patients after audio-visual stimulation. Brain, 128(12), 2830-42.

Bolognini, N., Rasi, F., \& Làdavas, E. (2005b). Visual localization of sounds. Neuropsychologia, 43(11), 1655-61.

Bolognini, N., Convento, S., Rossetti, A., \& Merabet, L. B. (2013). Multisensory processing after a brain damage: clues on post-injury crossmodal plasticity from neuropsychology. Neuroscience and Biobehavioral Reviews, 37(3), 269-78.

Brown, L. E., Kroliczak, G., Demonet, J. F., \& Goodale, M. A. (2008). A hand in blindsight: hand placement near target improves size perception in the blind visual field. Neuropsychologia, 46(3), 786-802.

Buma, F., Kwakkel, G., \& Ramsey, N. (2013). Understanding upper limb recovery after stroke. Restorative Neurology and Neuroscience, 31(6), 707-22.
Buxbaum, L. J., Ferraro, M. K., Veramonti, T., et al. (2004). Hemispatial neglect: subtypes, neuroanatomy, and disability. Neurology, 62(5), $749-56$.

Calamaro, N., Soroker, N., \& Myslobodsky, M. S. (1995). False recovery from auditory hemineglect produced by source misattribution of auditory stimuli (the ventriloquist effect). Restorative Neurology and Neuroscience, 7(3), 151-6.

Cappe, C., Morel, A., Barone, P., \& Rouiller, E. M. (2009). The thalamocortical projection systems in primate: an anatomical support for multisensory and sensorimotor interplay. Cerebral Cortex, 19(9), 2025-37.

Carey, L. M. (1995). Somatosensory loss after stroke. Crit Rev Phys Rehabil Med, 7(1), 51-91.

Carey, L. M., \& Matyas, T. A. (2011). Frequency of discriminative sensory loss in the hand after stroke in a rehabilitation setting. Journal of Rehabilitation Medicine, 43(3), 257-63.

Cecere, R., Romei, V., Bertini, C., \& Làdavas, E. (2014). Crossmodal enhancement of visual orientation discrimination by looming sounds requires functional activation of primary visual areas: a case study. Neuropsychologia, 56, 350-8.

Cohen, J. (1988). Statistical power analysis for the behavioral sciences (2nd ed.). Hillsdale: Lawrence Erlbaum.

Dancause, N., Barbay, S., Frost, S. B., et al. (2005). Extensive cortical rewiring after brain injury. Journal of Neuroscience, 25(44), 10167-79.

di Pellegrino, G., \& Frassinetti, F. (2000). Direct evidence from parietal extinction of enhancement of visual attention near a visible hand. Current Biology, 10(22), 1475-7.

Falchier, A., Schroeder, C. E., Hackett, T. A., et al. (2010). Projection from visual areas V2 and prostriata to caudal auditory cortex in the monkey. Cerebral Cortex, 20(7), 1529-38.

Fortenbaugh, F. C., VanVleet, T. M., Silver, M. A., \& Robertson, L. C. (2015). Spatial distortions in localization and midline estimation in hemianopia and normal vision. Vision Research, 111, 1-12.

Frassinetti, F., Pavani, F., \& Làdavas, E. (2002). Acoustical vision of neglected stimuli: interaction among spatially converging audiovisual inputs in neglect patients. Journal Cognitive Neuroscience, 14(1), 62-9.

Frassinetti, F., Bolognini, N., Bottari, D., Bonora, A., \& Làdavas, E. (2005). Audiovisual integration in patients with visual deficit. Journal Cognitive Neuroscience, 17(9), 1442-52.

Gallace, A., \& Spence, C. (2008). The cognitive and neural correlates of "tactile consciousness": a multisensory perspective. Consciousness and Cognition, 17(1), 370-407.

Gatchel, R. J., Lurie, J. D., \& Mayer, T. G. (2010). Minimal clinically important difference. Spine, 35(19), 1739-43.

Halligan, P. W., Fink, G. R., Marshall, J. C., \& Vallar, G. (2003). Spatial cognition: evidence from visual neglect. Trends in Cognitive Sciences, 7(3), 125-133.

Heilman, K. M., Valenstein, E., \& Watson, R. T. (2000). Neglect and related disorders. Seminars in Neurology, 20(4), 463-70.

Higgins, J. P., Altman, D. G., Gøtzsche, P. C., et al. (2011). The Cochrane collaboration's tool for assessing risk of bias in randomized trials. BMJ, 343, d5928.

Jiang, H., Stein, B. E., \& Mchaffie, J. G. (2015). Multisensory training reverses midbrain lesion-induced changes and ameliorates haemianopia. Nature Communications, 6, 7263.

Johansson, B. B. (2012). Multisensory stimulation in stroke rehabilitation. Frontiers in Human Neuroscience, 6, 60.

Kandel, E. R., Schwartz, J. H., \& Jessell, T. M. (Eds.). (2000). Principles of neural science (4th ed., pp. 1227-46). New York: McGraw-Hill.

Keller, I., \& Lefin-Rank, G. (2010). Improvement of visual search after audiovisual exploration training in hemianopic patients. Neurorehabilitation and Neural Repair, 24(7), 666-73. 
Keysers, C., Kohler, E., Umiltà, M. A., Nanetti, L., Fogassi, L., \& Gallese, V. (2003). Audiovisual mirror neurons and action recognition. Experimental Brain Research, 153(4), 628-36.

King, M. T. (2011). A point of minimal important difference (MID): a critique of terminology and methods. Expert Review of Pharmacoeconomics \& Outcomes Research, 11(2), 171-84.

Kinsbourne, M. (1993). Orientational bias model of unilateral neglect: Evidence from attentional gradients within hemispace. In I. H. Robertson \& J. C. Marshall (Eds.), Unilateral neglect: Clinical and experimental studies (pp. 63-86). Hove: Lawrence Erlbaum.

Klemen, J., \& Chambers, C. D. (2012). Current perspectives and methods in studying neural mechanisms of multisensory interactions. Neuroscience and Biobehavioral Reviews, 36(1), 111-33.

Kwakkel, G., Kollen, B., \& Lindeman, E. (2004). Understanding the pattern of functional recovery after stroke: facts and theories. Restorative Neurology and Neuroscience, 22(3-5), 281-99.

Làdavas, E., Berti, A., Ruozzi, E., \& Barboni, F. (1997). Neglect as a deficit determined by an imbalance between multiple spatial representations. Experimental Brain Research, 116(3), 493-500.

Laurienti, P. J., Kraft, R. A., Maldjian, J. A., Burdette, J. H., \& Wallace, M. T. (2004). Semantic congruence is a critical factor in multisensory behavioral performance. Experimental Brain Research, 158(4), 405-14.

Leo, F., Bolognini, N., Passamonti, C., Stein, B. E., \& Làdavas, E. (2008). Cross-modal localization in hemianopia: new insights on multisensory integration. Brain, 131(3), 855-65.

Levin, M. F., Kleim, J. A., \& Wolf, S. L. (2009). What do motor "recovery" and "compensation" mean in patients following stroke? Neurorehabilitation and Neural Repair, 23(4), 313-9.

Macaluso, E., Frith, C. D., \& Driver, J. (2000). Modulation of human visual cortex by crossmodal spatial attention. Science, 289(5482), 1206-8.

Martuzzi, R., Murray, M. M., Michel, C. M., et al. (2007). Multisensory interactions within human primary cortices revealed by BOLD dynamics. Cerebral Cortex, 17(7), 1672-9.

Mesulam, M. M. (1999). Spatial attention and neglect: parietal, frontal and cingulate contributions to the mental representation and attentional targeting of salient extrapersonal events. Philosophical Transactions of the Royal Society of London. Series B, Biological Sciences, 354(1387), 1325-46.

Nagy, A., Eördegh, G., Paróczy, Z., Márkus, Z., \& Benedek, G. (2006). Multisensory integration in the basal ganglia. European Journal of Neuroscience, 24(3), 917-24.

Newport, R., Hindle, J. V., \& Jackson, S. R. (2001). Links between vision and somatosensation. Vision can improve the felt position of the unseen hand. Current Biology, 11(12), 975-80.

Nijboer, T. C. W., Kollen, B. J., \& Kwakkel, G. (2013). Time course of visuospatial neglect early after stroke: a longitudinal cohort study. Cortex, 49(8), 2021-7.

Nijboer, T. C. W., Kollen, B. J., \& Kwakkel, G. (2014). The impact of recovery of visuo-spatial neglect on motor recovery of the upper paretic limb after stroke. PLoS ONE, 9(6), e100584.

Nudo, R. J., Wise, B. M., SiFuentes, F., \& Milliken, G. W. (1996). Neural substrates for the effects of rehabilitative training on motor recovery after ischemic infarct. Science, 272(5369), 1791-94.

Papageorgiou, E., Hardiess, G., Schaeffel, F., et al. (2007). Assessment of vision-related quality of life in patients with homonymous visual field defects. Graefes Archive for Clinical and Experimental Ophthalmology, 245(12), 1749-58.

Passamonti, C., Bertini, C., \& Làdavas, E. (2009a). Audio-visual stimulation improves oculomotor patterns in patients with hemianopia. Neuropsychologia, 47(2), 546-55.

Passamonti, C., Frissen, I., \& Làdavas, E. (2009b). Visual recalibration of auditory spatial perception: two separate neural circuits for perceptual learning. European Journal of Neuroscience, 30(6), 1141-50.
Pavlovskaya, M., Soroker, N., \& Bonneh, Y. (2007). Extinction is not a natural consequence of unilateral spatial neglect: evidence from contrast detection experiments. Neuroscience Letters, 420(3), 240-4.

Rockland, K. S., \& Ojima, H. (2003). Multisensory convergence in calcarine visual areas in macaque monkey. International Journal of Psychophysiology, 50(1-2), 19-26.

Sambo, C. F., Vallar, G., Fortis, P., et al. (2012). Visual and spatial modulation of tactile extinction: behavioural and electrophysiological evidence. Frontiers in Human Neuroscience, 6, 217.

Schendel, K., \& Robertson, L. C. (2004). Reaching out to see: arm position can attenuate human visual loss. Journal Cognitive Neuroscience, 16(6), 935-43.

Serino, A., Farnè, A., Rinaldesi, M. L., Haggard, P., \& Làdavas, E. (2007). Can vision of the body ameliorate impaired somatosensory function? Neuropsychologia, 45(5), 1101-7.

Shore, S. E. (2005). Multisensory integration in the dorsal cochlear nucleus: unit responses to acoustic and trigeminal ganglion stimulation. European Journal of Neuroscience, 21(12), 3334- 48.

Smith, D. T., Lane, A. R., \& Schenk, T. (2008). Arm position does not attenuate visual loss in patients with homonymous field deficits. Neuropsychologia, 46(9), 2320-25.

Soroker, N., Calamaro, N., \& Myslobodsky, M. (1995). McGurk illusion" to bilateral administration of sensory stimuli in patients with hemispatial neglect. Neuropsychologia, 33(4), 461-70.

Spreij, L. A., Visser-Meily, J. M., \& van Heugten, C. M. (2014). Nijboer TCW Novel insights into the rehabilitation of memory post acquired brain injury: a systematic review. Frontiers in Human Neuroscience, 8, 993.

Stein, B. E. (Ed.). (2012). The new handbook of multisensory processing. Cambridge: MIT Press.

Teasell R., \& Hussein N., (2014) Brain reorganization, recovery and organized care. In: Stroke rehabilitation clinician handbook. Retrieved August 26, 2015 from http://www.ebrsr.com.

Ten Brink, A. F., Nijboer, T. C. W., Bergsma, D. P., Barton, J. J. S., \& Van der Stigchel, S. (2015). Lack of multisensory integration in hemianopia: no influence of visual stimuli on aurally guided saccades to the blind hemifield. PLOS ONE, 10(4), e0122054.

Tijssen, J. G. P., \& Assendelft, W. J. J. (2008). Beoordeling van een gerandomiseerd effectonderzoek. In M. Offringa, W. J. J. Assendelft, \& R. J. P. M. Scholten (Eds.), Inleiding in evidencebased medicine (pp. 88-103). Houten: Bohn Stafleu van Loghum.

Ting, D. S., Pollock, A., Dutton, G. N., et al. (2011). Visual neglect following stroke: current concepts and future focus. Survey of Ophthalmology, 56(2), 114-34.

Van der Stoep, N., Visser-Meily, J. M., Kappelle, L. J., et al. (2013). Exploring near and far regions of space: distance-specific visuospatial neglect after stroke. J Clin Exp Neuropsyc, 35(8), 799-811.

Van der Stoep, N., Nijboer, T. C. W., Van der Stigchel, S., \& Spence, C. (2015). Multisensory interactions in the depth plane in front and rear space: a review. Neuropsychologia, 70, 335-49.

van Ee, R., van Boxtel, J. J., Parker, A. L., \& Alais, D. (2009). Multisensory congruency as a mechanism for attentional control over perceptual selection. Journal of Neuroscience, 29(37), $11641-9$.

van Vleet, T. M., \& Robertson, L. C. (2006). Cross-modal interactions in time and space: auditory influence on visual attention in hemispatial neglect. Journal Cognitive Neuroscience, 18(8), 1368-79.

Watkins, S., Shams, L., Tanaka, S., Haynes, J. D., \& Rees, G. (2006). Sound alters activity in human V1 in association with illusory visual perception. NeuroImage, 31(3), 1247-56.

Wilde, E. A., Hunter, J. V., \& Bigler, E. D. (2012). A primer of neuroimaging analysis in neurorehabilitation outcome research. NeuroRehabilitation, 31(3), 227-42.

Zamarian, L., Egger, C., \& Delazer, M. (2007). The mental representation of ordered sequences in visual neglect. Cortex, 43(4), 542-50. 